\title{
Grafting of a novel gold(III) complex on nanoporous MCM-4I and evaluation of its toxicity in Saccharomyces cerevisiae
}

This article was published in the following Dove Press journal:

International Journal of Nanomedicine

9 December 201 I

Number of times this article has been viewed

\author{
Yousef Fazaeli ${ }^{1,2}$ \\ Mostafa M Amini' \\ Hamed Ashourion ${ }^{3}$ \\ Homayoun Heydari² \\ Abbas Majdabadi² \\ Amir Reza Jalilian² \\ Shamsozoha Abolmaali ${ }^{2,3}$ \\ 'Department of Chemistry, Faculty of \\ Sciences, Shahid Beheshti University, \\ Evin, Tehran, ${ }^{2}$ Agricultural, Medical and \\ Industrial Research School, Moazzen \\ Boulevard, Rajaee Shahr, Karaj, \\ ${ }^{3}$ Department of Biotechnology, Faculty \\ of New Technologies and Engineering, \\ Shahid Beheshti University, Evin, \\ Tehran, Iran
}

\begin{abstract}
The goal of this research was to investigate the potential of newly synthesized gold complex trichloro(2,4,6-trimethylpyridine)Au(III) as an anticancer agent. The gold(III) complex was synthesized and grafted on nanoporous silica, MCM-41, to produce $\mathrm{AuCl}_{3} @ \mathrm{PF}-$ MCM-41 ( $\mathrm{AuCl}_{3}$ grafted on pyridine-functionalized MCM-41). The toxicity of trichloro(2,4,6trimethylpyridine)Au(III) and $\mathrm{AuCl}_{3} @ \mathrm{PF}-\mathrm{MCM}-41$ in Saccharomyces cerevisiae (as a model system) was studied. The gold(III) complex showed a mid cytotoxic effect on yeast viability. Using the drug delivery system, nanoporous MCM-41, the gold(III) complex became a strong inhibitor for growth of yeast cells at a very low concentration. Furthermore, the animal tests revealed a high uptake of $\mathrm{AuCl}_{3} @$ PF-MCM-41 in tumor cells. The stability of the compound was confirmed in human serum.
\end{abstract}

Keywords: trichloro(2,4,6-trimethylpyridine)Au(III), MCM-41, Au(III), Saccharomyces cerevisiae, anticancer agent

\section{Introduction}

The strong anticancer effects of cisplatin demonstrated that other metal-based compounds might have the potential to act as anticancer agents. ${ }^{1,2}$ The isoelectronic and isostructural with $\mathrm{Pt}(\mathrm{II}) ; \mathrm{Au}(\mathrm{III})$, is a suitable candidate to defeat cancer cells. While $\mathrm{Au}(\mathrm{III})$ analogs will easily reduce to metallic gold under physiological conditions, ${ }^{3}$ in the early 1990s, a few gold compounds were prepared and characterized for their antitumor activity with positive results. ${ }^{4,5}$ Recently, using various $\mathrm{Au}(\mathrm{III})$ complexes with novel functionality has elicited more interest due to their distinct physical and chemical properties, stability under physiological conditions, and outstanding cytotoxic effects. ${ }^{6,7}$

The toxicity of gold complexes originates from two aspects: interactions with the negatively charged cell and subcellular membranes; and from the fact that trapped particles in vesicles are able to disrupt the membrane. ${ }^{8}$ Using endocytotic mechanisms most of the nanoparticle bioconjugates enter the cells in a manner dependent on size and shape. ${ }^{9-13}$ Following the absorption, these nanoparticles need to reach their subcellular targets to be effective. To increase the efficiency of uptake and prevent aggregation, the gold complexes can be loaded on a drug delivery system. ${ }^{11}$

The potential of pyridine-Au(I) compounds for practical application has recently been demonstrated. ${ }^{14}$ Spasmolytic, diuretic, anticoagulant, anticancer, and antianaphylactic activities of pyrans were reported. ${ }^{15-17}$ Moreover, the antitumor
Correspondence: Shamsozoha Abolmaali Faculty of Science, Department of Cell and Molecular Biology, Semnān University, Semnān 35I3I-191II, Iran $\mathrm{Tel} / \mathrm{Fax}+9823$ I3 354057

Email s_abolmaali@semnan.ac.ir 
activities of a series of pyridine, pyrane, and pyrimidine derivatives have been evaluated on 59 different human tumor cell lines. Some of the pyridine-based compounds are highly selective and inhibit leukemia cell lines. ${ }^{18}$

In this study, 2,4,6-trimethylpyridine was reacted with $\mathrm{HAuCl}_{4}$ to produce trichloro(2,4,6-trimethylpyridine) $\mathrm{Au}(\mathrm{III})$ complex. To provide an efficient amount of trichloro(2,4,6-trimethylpyridine)Au(III) inside the cells, the complex was loaded on a nanoporous MCM-41 drug delivery system. Nanoporous MCM-41 is absorbed efficiently by various mammalian cells. ${ }^{13,19}$ The nanoporous silica features a high surface area $\left(1064 \mathrm{~m}^{2} / \mathrm{g}\right)$, large pore volume $(0.9 \mathrm{~mL} / \mathrm{g})$, tunable pore size $(2-10 \mathrm{~nm})$, and good chemical stability. ${ }^{13,19}$ In addition, the biocompatibility of nanoporous MCM-41 with and without surface functionalization has been assayed in different procedures. ${ }^{6}$ The authors have previously introduced nanoporous MCM-41 as an acceptable host for grafting of complexes with optical properties. ${ }^{19}$

Saccharomyces cerevisiae was used to test the toxicity of trichloro(2,4,6-trimethylpyridine)Au(III) in vivo. It is an excellent model system to investigate mechanisms of drug resistance and toxicity. Most of the human enzymatic and cellular structures, the oxidative stress response, and the family of drug resistance pumps are also present in yeast. ${ }^{20}$ As well as biodistribution and stability, analyses were performed in five Sprague Dawley ${ }^{\circledR}$ rats bearing breast tumor and human serum.

\section{Materials and methods Materials}

All chemicals were purchased either from Sigma-Aldrich ${ }^{\circledR}$ (St Louis, MO) or Merck Chemicals (Darmstadt, Germany) and used without further purification. All reactions and manipulations were carried out in an atmosphere of dry nitrogen, using standard Schlenk techniques. Solvents were dried and distilled under nitrogen prior to use, according to standard procedures. Nanoporous MCM-41 was synthesized, as previously reported. ${ }^{21}$ Infrared spectra were recorded
(KBr pellets) on a Shimadzu FTIR 4600spectrometer (Kyoto, Japan). The elemental analyses (carbon hydrogen nitrogen [CHN]) were performed on a Thermo Finnigan Flash EA TM 1112 microanalyzer (San Jose, CA). All samples were dried in an atmosphere of dry nitrogen, using standard Schlenk techniques before analysis at $300^{\circ} \mathrm{C}$ for 3 hours. Low-angle X-ray diffraction (XRD) patterns were obtained on a Philips Analytical PW-17C diffractometer (Eindhoven, The Netherlands) with $\mathrm{Cu} \mathrm{K} \alpha$ radiation. Scans were performed from $(2 \theta) 1^{\circ}$ to $10^{\circ}$ at a rate of $3^{\circ}$ minute. Thermal analysis was carried out on a Rheometric Scientific Simultaneous Thermal Analyzer 1500 (Leatherhead, Surrey, UK) with a heating rate of $10^{\circ} \mathrm{C} / \mathrm{minute}$ in air. The photoluminescence spectra were carried out using the second (532 nm) harmonic of a Ocean Optic USB2000-FLG spectrofluorometer (Dunedin, FL) with Nd:YAG laser for excitation.

\section{Synthesis}

Preparation of trichloro(2,4,6-trimethylpyridine) $\mathrm{Au}(\mathrm{III})$

Two millimole of 2,4,6-trimethylpyridine in $10 \mathrm{~mL}$ methanol was added to $2 \mathrm{mM}(0.80 \mathrm{~g})$ of $\mathrm{HAuCl}_{4} \cdot 3 \mathrm{H}_{2} \mathrm{O}$ in $10 \mathrm{~mL}$ of acetonitrile. The resulting deep yellow solution was stirred at $40^{\circ} \mathrm{C}$ for 30 minutes followed by filtration. In about 7 days, yellow crystals appeared by simple evaporation. Infrared (KBr Disk, cm ${ }^{-1}$ ): 3433 s, 3054 w, 2922 w, 2843 w, 1623 m, 1545 m, 1464 m, 1401 w, 1368 m, 1309 w, 1246 w, 1034 m, 936 w, 857 m, 704 m, 536 w, 463 w. Ultraviolet-visible spectrometry: 217,265 , and melting point $>573^{\circ} \mathrm{C}$.

\section{Preparation of $\mathrm{AuCl}_{3} @ P F-M C M-4 \mathrm{I}$ \\ Preparation of pyridine-functionalized MCM-4I (PF-MCM-4)}

Eight millimole 4-methylpyridine in tetrahydrofuran (THF) was mixed with one equivalent of lithium diisopropylamine in a total volume of $80 \mathrm{~mL}$ THF at $40^{\circ} \mathrm{C}$ for 2 hours (Figure 1). The yielded brown solution was chilled $\left(20^{\circ} \mathrm{C}\right)$,

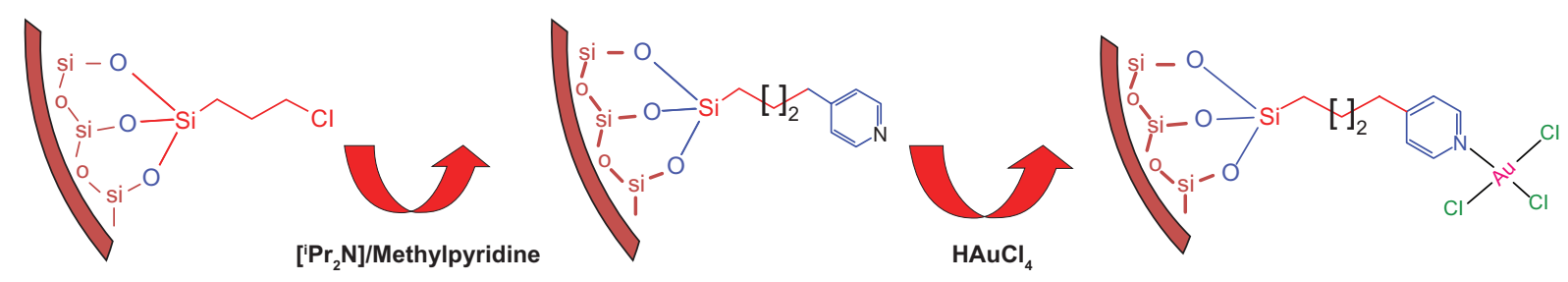

Figure I Schematic procedure of grafting Au(III) complex on pyridine-functionalized MCM-4I. 
treated with 2.0 g MCM-41-grafted chloropropylsilyl groups, and stirred for 72 hours at $4{ }^{\circ} \mathrm{C}$. The pale pellet was washed three times with absolute ethanol and diethyl ether followed by drying in $1 \mathrm{mmHg}$ at room temperature for 48 hours. A pyridine loading of $0.2 \mathrm{mM} \mathrm{g}^{-1}$ was obtained for PF-MCM-41 as found by carbon and nitrogen analysis (CHN: C, 2.05; $\mathrm{H}, 0.30 ; \mathrm{N}, 0.27) .^{22}$

\section{Grafting of $\mathrm{HAuCl}_{4}$ on PF-MCM-4I}

One gram of fresh dried PF-MCM-41 was treated with equivalent mole of $\mathrm{HAuCl}_{4} \cdot 3 \mathrm{H}_{2} \mathrm{O}(0.2 \mathrm{mM}, 0.08 \mathrm{~g}$ in $10 \mathrm{~mL}$ acetonitrile) in a medium of $25 \mathrm{~mL}$ dried methanol. The pale rose suspension was stirred for 5 hours then washed copiously with water. After filtration and drying under vacuum at room temperature for 3 hours, the $\mathrm{AuCl}_{3} @ \mathrm{PF}-\mathrm{MCM}-41$ was obtained.

\section{Cytotoxicity test in yeast cells}

To test the biological properties of trichloro(2,4,6-trimethylpyridine)Au(III), a MATa type of $S$. cerevisiae was used. A 48 -hour colony of this yeast was grown in $1 \%$ yeast extracts, $2 \%$ meat peptone, and $2 \%$ dextrose (here, glucose) $(\mathrm{YPD})^{23}$ for 16 hours at $30^{\circ} \mathrm{C}$. A cell density of $\mathrm{OD}_{600} 0.05$ was inoculated in $100 \mathrm{~mL}$ fresh YPD media for 2 hours $\left(30^{\circ} \mathrm{C}\right.$ and $200 \mathrm{rpm}$ ) to have the cells at a logarithmic phase of growth. An initial cell density of $\mathrm{OD}_{600} 0.01$ from the 2-hour-old culture was supplemented with $0,5,7,10,15,20,22$, and $25 \mathrm{mM}$ of the trichloro(2,4,6-trimethylpyridine)Au(III), 0 , $0.15,0.25,0.5,1,2,3,5,10,20$, and 25 mM AuCl${ }_{3} @ \mathrm{PF}-$ MCM-41, and 0, 0.1, 0.5, 1, 5, and 10 mM MCM-41. All treatments were incubated at $30^{\circ} \mathrm{C}$ in a rotary shaker with $200 \mathrm{rpm}$ for 24 hours. The $\mathrm{OD}_{600}$ of the cells was measured 12 times at 2-hour intervals and in three independent repeats. The resulting growth curve represented the average optical density of the yeast cells. The $\mathrm{IC}_{50}$ (half-maximal inhibitory concentration) for trichloro(2,4,6-trimethylpyridine) $\mathrm{Au}(\mathrm{III})$ and $\mathrm{AuCl}_{3} @ \mathrm{PF}-\mathrm{MCM}-41$ was calculated based on their growth rates.

\section{Biodistribution and stability analyses}

Animal assays were performed in accordance with the United Kingdom Biological Council's Guidelines on the Use of Living Animals in Scientific Investigations. ${ }^{24}$ Five Sprague Dawley rats (8-10 weeks of age; average body weight $320 \pm 5 \mathrm{~g}$ ) bearing breast tumor received $25 \mathrm{mg} / \mathrm{kg} \mathrm{AuCl} @$ PF-MCM-41, or equal volume of double distilled water, to control counterparts via tail vein injection. The rats were maintained at $22^{\circ} \mathrm{C}-24^{\circ} \mathrm{C}$ with a 12 -hour light:dark cycle, and were provided with drinking water and fed ad libitum for 24 hours. The animals were sacrificed by $\mathrm{CO}_{2}$ asphyxiation followed by excising the tumor and taking blood for comparative analyses. Tumors were weighed, rinsed in a normal saline buffer, and crushed in liquid nitrogen. Serums were prepared from centrifugation of coagulated blood. The aqua from tumor cells and serums were assayed for emission standard peak of $\mathrm{AuCl}_{3} @ \mathrm{PF}-\mathrm{MCM}-41$.

\section{In vitro stability test}

Serum samples were incubated with $2 \mathrm{mM}$ of $\mathrm{AuCl}_{3} @ \mathrm{PF}$ MCM-41 at $37^{\circ} \mathrm{C}$ in shaker incubators (100 rpm) for 24 and 48 hours. The infrared (IR) analyses were carried out for $\mathrm{AuCl}_{3} @ \mathrm{PF}-\mathrm{MCM}-41$, as described above.

\section{Results}

A new complex of gold(III), trichloro(2,4,6-trimethyl -pyridine)Au(III), was synthesized and analyzed for chemical structure. To provide enough of the complex inside cells, nanoporous MCM-41 drug delivery system was used to produce $\mathrm{AuCl}_{3} @ \mathrm{PF}-\mathrm{MCM}-41$. Cytotoxicity of trichloro(2,4,6-trimethylpyridine)Au(III) and $\mathrm{AuCl}_{3} @$ PF-MCM-41 were studied in S. cerevisiae. Biodiversity and stability of $\mathrm{AuCl}_{3} @ \mathrm{PF}-\mathrm{MCM}-41$ were evaluated in rats bearing breast tumor and human serums.

\section{Synthesis of (2,4,6-trimethylpyridine) $\mathrm{Au}(\mathrm{III})$ complex}

The title complex was prepared by reacting $\mathrm{HAuCl}_{4} \cdot 3 \mathrm{H}_{2} \mathrm{O}$ to corresponding ligand (1:1 equivalent ratio) in a mixture of methanol and acetonitrile at $40^{\circ} \mathrm{C}$. The progress of the reaction was followed by the appearance of a very intense yellow fluorescence. The massive crystallization of the product in a form of plate crystals occurred after about 7 days at $30^{\circ} \mathrm{C}$. Pyridine and its derivatives coordinated directly to the gold center in a square planer form, and neither hydrogen transfer nor polymerization occurred. ${ }^{25-27}$ Presence of the gold(III) complex on MCM-41 was confirmed using IR and CHN.

\section{Photoluminescence measurements and absorption spectrum}

The photoluminescence properties of the gold(III) complex were measured in aqueous solution. As previously reported, ${ }^{28}$ in all cases the luminescent excited states were apparently intraligand triplets (436.93, 465.4, and $496.87 \mathrm{~nm}$ ). Attachment of an electron withdrawing nitrogen substituent to the aromatic ring with three electron donors methyl groups resulted in blue-shifted emission with respect to pyridine ${ }^{29}$ 
and confirmed formation of trichloro(2,4,6-trimethylpyridine)Au(III) complex.

$\mathrm{Au}(\mathrm{III})$ with $\mathrm{d}^{8}$ electronic configuration adopts an assortment of square-planar geometry, which leads to ligand field transitions. ${ }^{30} \mathrm{Au}(\mathrm{III})$ center is an oxidized species, therefore, low-energy ligand to metal charge transfer (LMCT) transitions are quite common in contrast to metal to ligand charge transfer (MLCT) transitions.

\section{XRD patterns}

Figure 2 illustrates the low angle XRD patterns of PFMCM-41 and $\mathrm{AuCl}_{3} @ \mathrm{PF}-\mathrm{MCM}-41$. The cell parameters $\left(\mathrm{a}_{0}=2 \mathrm{~d}_{100} / \sqrt{ } 3\right)$ of 4.18 and $4.10 \mathrm{~nm}$, were calculated for PF-MCM-41 and $\mathrm{AuCl}_{3} @$ PF-MCM-41, respectively. Both patterns exhibit a high-intensity (100) reflection within $2 \theta$ in the range of $2^{\circ}-3^{\circ}$. The similar $\mathrm{d}_{100}$ spacing values indicated that the two-dimensional hexagonal nanoporous structures $\left(\mathrm{P}_{6 \mathrm{~mm}}\right)$ of MCM-41 were maintained after introducing the gold(III) complex. ${ }^{31}$ In comparison with MCM-41 diffraction, intensity of the grafted materials decreased significantly $\left(\mathrm{a}_{0}=4.36 \mathrm{~nm}\right)$; this, along with the decrease in surface areas (in situ), showed that the nanoporous channels were occupied by the gold complex.

\section{Toxicity test in vivo}

The 24-hour growth curves of $S$. cerevisiae were generated in liquid YPD supplemented with a different amount of trichloro(2,4,6-trimethylpyridine)Au(III), AuCl $@$ @PFMCM-41, and nanoporous MCM-41 as a control. The results are presented in Figures 3-6. Logical decreases were observed in the growth rate of yeast cells treated with 5-25 $\mathrm{mM}$ trichloro(2,4,6-trimethylpyridine)Au(III) (Figure 3). Lower amounts of the complex (5 and $7 \mathrm{mM}$ ) revealed almost no toxic effect on the treated cells (Figure 4), while higher concentrations up to $15 \mathrm{mM}$ obviously limited the growth rate (Figure 5). Twenty to twenty-five millimolar of trichloro(2,4,6-trimethylpyridine)Au(III) fully inhibited

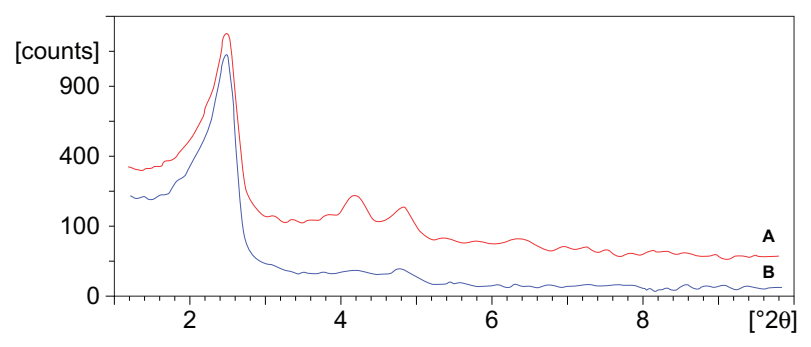

Figure 2 X-ray diffraction patterns of PF-MCM-4I (A) and AuCl @PF-MCM-4I (B). The patterns exhibit a high intensity $(100)$ reflection within the $2 \theta$ range of $2^{\circ}-3^{\circ}$. The similar $d_{100}$ spacing values confirmed the maintenance of two-dimensional hexagonal mesoporous structures $\left(\mathrm{P}_{6 \mathrm{~mm}}\right)$ of MCM-4I after introducing complexes. growth of yeast (Figure 6). The $\mathrm{IC}_{50}$ for trichloro(2,4,6trimethylpyridine)Au(III) was about $12 \mathrm{mM}$.

Yeast cells showed growth inhibition at $\mathrm{AuCl}_{3} @ \mathrm{PF}-$ MCM-41 concentration of $1 \mathrm{mM}$ and higher where they tolerated $15 \mathrm{mM}$ trichloro(2,4,6-trimethylpyridine)Au(III) (Figure 5). As is shown in Figure 4, yeast tolerated 0.15 and $0.25 \mathrm{mM}$ of $\mathrm{AuCl}_{3} @ \mathrm{PF}-\mathrm{MCM}-41$. Cells behaved nearly the same under treatment of 20-25 mM AuCl @PF-MCM-41 and trichloro(2,4,6-trimethylpyridine)Au(III) (Figure 6). The $\mathrm{IC}_{50}$ for $\mathrm{AuCl}_{3} @ \mathrm{PF}-\mathrm{MCM}-41$ dropped about 50 times to nearly $0.25 \mathrm{mM}$ in comparison with trichloro(2,4,6trimethylpyridine)Au(III) (Figures 4 and 5).

The presence of different amount of nanoporous MCM-41 had no toxic effects on yeast growth (Figures 4-6).

\section{Biodistribution and stability analyses}

$\mathrm{AuCl}_{3} @ \mathrm{PF}-\mathrm{MCM}-41$ was well tolerated in rats at a dose of $25 \mathrm{mg} / \mathrm{kg}$. In comparison to the control group, no abnormalities in feeding and other behaviors were observed. Biodistribution studies revealed a higher tumor uptake within 24 hours compared to the blood tissue. The average tumor uptake was 3.8 to that of blood ( $\mathrm{mMol} / \mathrm{mMol})$.

To investigate in vitro stability of $\mathrm{AuCl}_{3} @ \mathrm{PF}-\mathrm{MCM}-41$, the treated human blood serums were analyzed with IR. The results confirmed stability of $\mathrm{AuCl}_{3} @ \mathrm{PF}-\mathrm{MCM}-41$ in human serum within 24 and 48 hours.

\section{Discussion}

To maximize the toxic effects of gold(III) on cells, a new complex of gold(III), trichloro(2,4,6-trimethylpyridine) $\mathrm{Au}(\mathrm{III})$, was synthesized and grafted on nanoporous MCM-41. Its toxicity in $S$. cerevisiae, biodiversity in rat bearing breast tumor, and stability in human serum was evaluated in this study.

Trichloro(2,4,6-trimethylpyridine)Au(III) complex did not inhibit yeast growth as previously reported for $\mathrm{HAuCl}_{4}{ }^{32}$ One and a half millimolar $\mathrm{HAuCl}_{4} \cdot 3 \mathrm{H}_{2} \mathrm{O}$ completely retarded the growth of yeast cells, ${ }^{32}$ whereas trichloro(2,4,6trimethylpyridine)Au(III) at a similar concentration of gold had no toxic effect on the cells. The differentiation in toxicity of these materials most likely originates from their interactions with the negatively charged cell membranes. Based on the results reported by De la Fuente et al, ${ }^{11}$ the aggregation of trichloro(2,4,6-trimethylpyridine)Au(III) under physiological conditions may lead to fewer inhibitory effects than $\mathrm{HAuCl}_{4}$ on yeast cells.

To identify whether a drug delivery system changes the toxicity of trichloro(2,4,6-trimethylpyridine) $\mathrm{Au}(\mathrm{III})$, the 

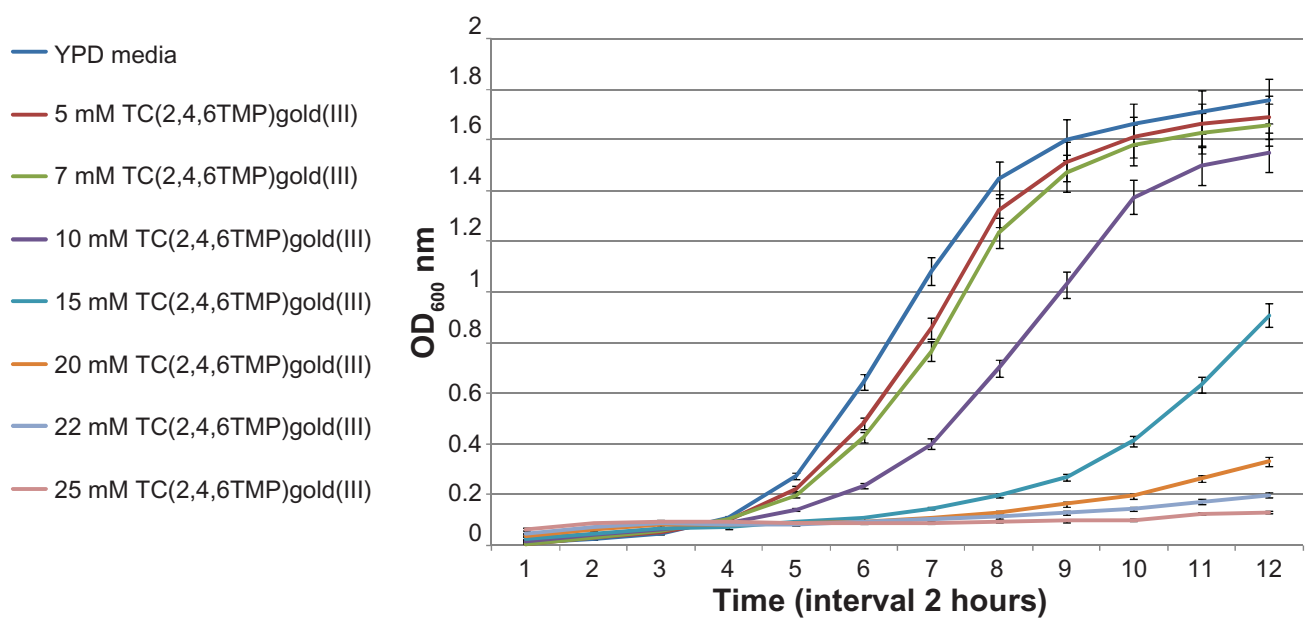

Figure 3 Growth inhibition of yeast cells by adding the indicated amounts of trichloro(2,4,6-trimethylpyridine)Au(III). Using 5-25 mM trichloro(2,4,6-trimethylpyridine) $\mathrm{Au}(\mathrm{III})$ logical decreases were observed in growth rate.

Abbreviation: TC(2,4,6TMP)gold(III), trichloro(2,4,6-trimethylpyridine)Au(III)
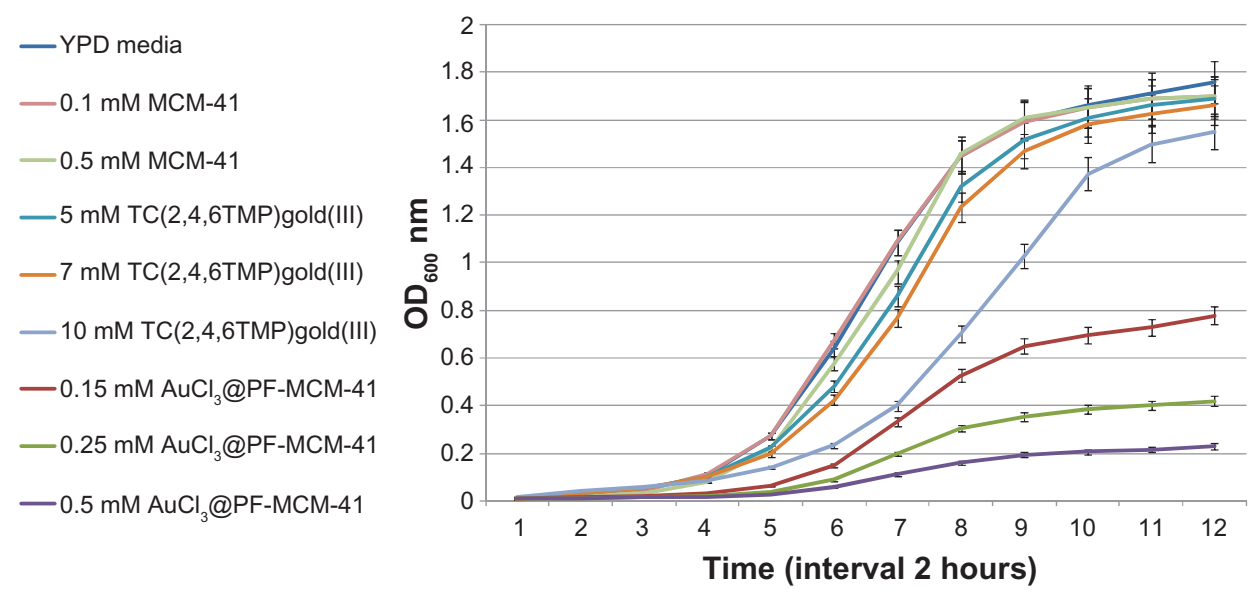

Figure 4 Growth curves of yeast cells by adding the low amounts of MCM-4I, trichloro(2,4,6-trimethylpyridine)Au(III), AuCl @PF-MCM-4I. 5 and 7 mM of TC(2,4,6TMP) gold(III) showed no toxic effect on the treated cells while 0.15 mM AuCl @PF-MCM-4I limited growth rate of the cells stronger than I0 mM TC(2,4,6TMP)gold(III). Abbreviation: TC(2,4,6TMP)gold(III), trichloro(2,4,6-trimethylpyridine)Au(III).
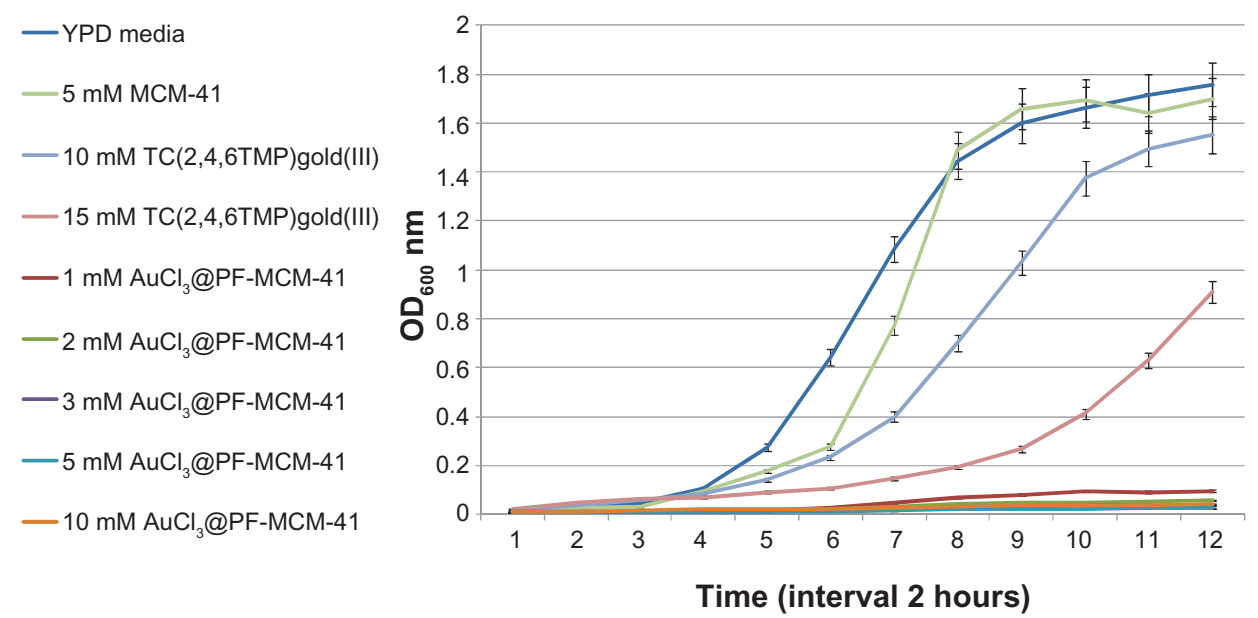

Figure 5 Growth curves of yeast cells by adding the moderate amounts of MCM-4I, trichloro(2,4,6-trimethylpyridine)Au(III) and AuCl @PF-MCM-4I. The cells grew about control in YPD media under the condition of 5 mM MCM-4I. Up to 15 mM TC(2,4,6TMP)gold(III) was tolerated. I mM was growth rate inhibition threshold for AuCl $@$ PF-MCM-4I.

Abbreviation: TC(2,4,6TMP)gold(III), trichloro(2,4,6-trimethylpyridine)Au(III). 

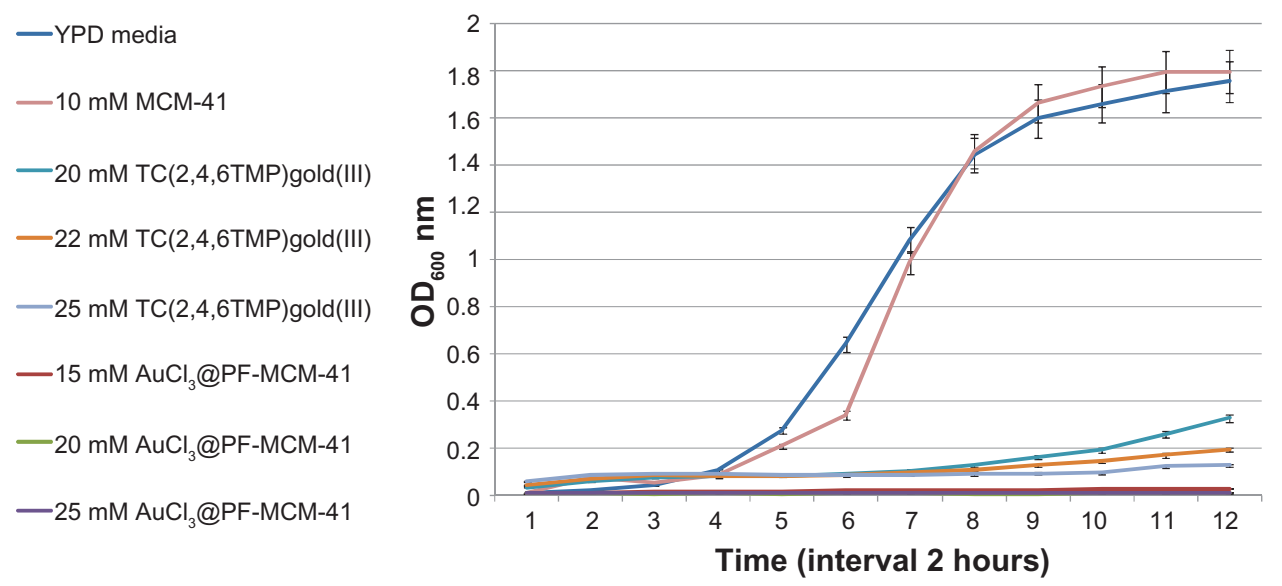

Figure 6 Growth curves of yeast cells by adding the high amounts of MCM-4I, trichloro(2,4,6-trimethylpyridine)Au(III) and AuCl $@ P F-M C M-4 I$. Growth of yeast cells inhibited by adding 25 mM TC(2,4,6TMP)gold(III), as well as 25 mM AuCl @PF-MCM-4I.

Abbreviation: TC(2,4,6TMP)gold(III), trichloro(2,4,6-trimethylpyridine)Au(III).

$\mathrm{Au}(\mathrm{III})$ complex was grafted on $\mathrm{MCM}-41$ to produce $\mathrm{AuCl}_{3} @$ PF-MCM-41. MCM-41, with pore size of 10-60 nm, are uptaken by mammalian, yeast, and bacteria cells through the endocytosis mechanism. ${ }^{13}$ No cytotoxicity effects have been shown by introducing nanoporous MCM-41 to cells. ${ }^{13}$ In this study, the growth curves for yeast at a MCM-41 concentration of $0.1,0.5,5$, and $10 \mathrm{mM}$ confirmed this evidence (Figures 4-6). Although, the $\mathrm{OD}_{600} \mathrm{~nm}$ of the cell suspensions treated with 0.15 mM AuCl $3 @$ PF-MCM-41 depleted to a maximum of 0.7 . Yeast cells were hypersensitive to $0.5 \mathrm{mMAuCl} @$ @PF-MCM-41 but not susceptible to 5 and $7 \mathrm{mM}$ trichloro(2,4,6-trimethylpyridine)Au(III) (Figure 4), suggesting that the nanoporous MCM-41 makes the gold(III) complex a strong cell killing agent.

\section{Conclusion}

The combined results of this study show that the grafting of $0.2 \mathrm{mM}$ trichloro(2,4,6-trimethylpyridine) $\mathrm{Au}(\mathrm{III})$ on $1.0 \mathrm{~g} \mathrm{MCM}^{-41}$ dropped the $\mathrm{IC}_{50}$ about 50-fold to the $\mathrm{IC}_{50}$ of $0.25 \mathrm{mM}$. These data, in comparison with those from $\mathrm{HAuCl}_{4}$ complex, ${ }^{32}$ reveal the toxic effects of trichloro(2,4,6-trimethyl pyridine)Au(III) on S. cerevisiae. In addition, they confirm the role of nanoporous MCM-41 in delivery of the gold(III) complex to their target(s) in cells. The tested complexes were toxic to the cells as MCM-41 < trichloro(2,4,6-trimethylpyridine) $\mathrm{Au}(\mathrm{III})<\mathrm{AuCl}_{3} @ \mathrm{PF}-\mathrm{MCM}-41$. These results also confirmed zero premature release of trichloro(2,4,6-trimethylpyridine) $\mathrm{Au}(\mathrm{III})$. The toxicity of $\mathrm{AuCl}_{3} @ \mathrm{PF}-\mathrm{MCM}-41$ on yeast cells comes from guaranteed transferring, preventing aggregation, and most probably reaching target biomolecules of the gold complex. Furthermore, the preliminary animal tests featured relatively good tumor uptake without utilizing a selective tumor delivery system (tumor to blood uptake ratio $=3.8$ ). The stability test in human serum, showed that $\mathrm{Au}$ (III) moiety stabilized significantly at neutral $\mathrm{pH}$ through an appropriate choice of ligand and interface ligand on nanoporous silica while preserving its chemical and biological properties.

Without any experimental evidence for subcellular localization of and drug release from $\mathrm{AuCl}_{3} @ \mathrm{PF}-\mathrm{MCM}-41$, it is thought that the mode of action is dependent on free $\mathrm{AuCl}_{3} @ \mathrm{PF}-\mathrm{MCM}-41$ in cytosol or most probably in the nucleus. The high cytotoxic effects of $\mathrm{AuCl}_{3} @ \mathrm{PF}-\mathrm{MCM}-41$, low cytotoxicity of trichloro(2,4,6-trimethylpyridine)Au(III) (Figures 5 and 6) in case of undesired release under physiological conditions, and the stability of $\mathrm{AuCl}_{3} @ \mathrm{PF}-\mathrm{MCM}-41$ in serum all suggest the potential of trichloro(2,4,6-trimethylpyridine)Au(III) as a cell killer for cancer therapy.

\section{Acknowledgment}

This research was supported by the Deputy for Research, Shahid Beheshti University, Tehran, Iran.

\section{Disclosure}

The authors report no conflicts of interest in this work.

\section{References}

1. Lippert B. Cisplatin: Chemistry and Biochemistry of a Leading Anticancer Drug. New York: John Wiley and Sons; 1999.

2. Wong E, Giandomenico CM. Current status of platinum-based antitumor drugs. Chem Rev. 1999;99(9):2451-2466.

3. Gabbiani C, Casini A, Messori L. Gold(III) compounds as anticancer drugs. Gold Bull. 2007;40(1):73-81.

4. Parish RV, Howe BP, Wright JP, et al. Chemical and biological studies of dichloro(2-[(dimethylamino)methyl)phenyl] gold(III). Inorg Chem. 1996;35(6):1659-1666.

5. Buckley RG, Elsome AM, Fricker SP, et al. Antitumor properties of some 2-[(dimethylamino)methyl]phenylgold(III) complexes. J Med Chem. 1996;39(26):5208-5214. 
6. Bhattacharya R, Mukherjee P. Biological properties of "naked" metal nanoparticles. Adv Drug Deliv Rev. 2008;60(11):1289-1306.

7. Marcon G, Messori L, Orioli P, et al. Reactions of gold(III) complexes with serum albumin. Eur J Biochem. 2003;270(23):4655-4661.

8. Goodman CM, McCusker CD, Yilmaz T, et al. Toxicity of gold nanoparticles functionalized with cationic and anionic side chains. Bioconjug Chem. 2004;15(4):897-900.

9. Murphy CJ, Gole AM, Stone JW, et al. Gold nanoparticles in biology: beyond toxicity to cellular imaging. Acc Chem Res. 2008;41(12): 1721-1730.

10. Lévy R, Shaheen U, Cesbron Y, et al. Gold nanoparticles delivery in mammalian live cells: a critical review. Nano Rev. 2010;1:4889.

11. De la Fuente JM, Berry CC, Riehle MO, et al. Nanoparticle targeting at cells. Langmuir. 2006;22(7):3286-3293.

12. Chen Z, Xu R, Zhang Y, et al. Effects of proteins from culture medium on surface property of silanes-functionalized magnetic nanoparticles. Nanoscale Res Lett. 2008;4(3):204-209.

13. Slowing I, Trewyn BG, Lin VS, et al. Effect of surface functionalization of MCM-41-type mesoporous silica nanoparticles on the endocytosis by human cancer cells. J Am Chem Soc. 2006;128(46):14792-14793.

14. Fernández EJ, Laguna A, López-de-Luzuriaga J, et al. Pyridine gold complexes: an emerging class of luminescent materials. Gold Bull. 2007;40(3):172-183

15. Andreani LL, Lapi E. Aspects and orientations of modern pharmacognosy Boll Chim Farm. 1960;99:583-586.

16. Bonsignore L, Loy G, Secci D, et al. Synthesis and pharmacological activity of 2-oxo-(2H)1-benzopyran-3-carboxamide derivatives. Eur J Med Chem. 1993;28(6):517-520.

17. Witte EC, Neubert P, Roesch A. 7-(piperazinyl propoxy)-2H-1benzopyran-2-ones. Ger Offen, DE 3427985. Chem Abstr. 1986;104: $224915 f$.

18. Amr AG, Mohamed AM, Mohamed SF, et al. Anticancer activities of some newly synthesized pyridine, pyrane, and pyrimidine derivatives. Bioorg Med Chem. 2006;14(16):5481-5488.

19. Fazaeli Y, Amini MM, Mohajerani E, et al. Grafting aluminum(III) 8-hydroxyquinoline derivatives on MCM-41 mesoporous silica for tuning of the light emitting color. J Colloid Interface Sci. 2010;346(2): 384-390.

20. Decottignies A, Goffeau A. Complete inventory of the yeast ABC proteins. Nat Genet. 1997;15(2):137-145.
21. Tanev PT, Pinnavaia TJ. Mesoporous silica molecular sieves prepared by ionic and neutral surfactant templating: a comparison of physical properties. Chem Mater. 1996;8(8):2068-2079.

22. Shaabani A, Mohammadpour Amini M, Ghasemi S, et al. Pyridinefunctionalized MCM-41 as an efficient and recoverable catalyst for the synthesis of pyran annulated heterocyclic systems. Chem Pharm Bull (Tokyo). 2010;58(2):270-272.

23. Sherman F, Fink GR, Hicks JB. Methods in Yeast Genetics. New York: Cold Spring Harbor Laboratory; 1986.

24. Biological Council. Guidelines on the Use of Living Animals in Scientific Investigations. 2nd ed. London: Biological Council; 1987.

25. Bourosh P, Bologa O, Simonov Y, et al. Synthesis and structure of products of interaction of $\mathrm{H}\left[\mathrm{AuCl}_{4}\right]$ with $\mathrm{H}_{2} \mathrm{DMG}$ and pyridine. Inorg Chim Acta. 2007;360(10):3250-3254

26. Adams H-N, Strähle J. Die Pyridinaddukte der Goldhalogenide. 1. Darstellung und Struktur von $[\mathrm{Hpy}]\left[\mathrm{AuCl}_{4}\right], \mathrm{AuCl}_{3} \cdot \mathrm{py},\left[\mathrm{AuCl}_{2}(\mathrm{py})_{2}\right]$ $\mathrm{Cl} \cdot \mathrm{H}_{2} \mathrm{O}$ and $\left[\mathrm{AuCl}_{2}(\mathrm{py})_{2}\right]\left[\mathrm{AuCl}_{2}\right]$ [Pyridine adducts of the gold halides. 1. Synthesis and Structure of $[\mathrm{Hpy}]\left[\mathrm{AuCl}_{4}\right], \mathrm{AuCl}_{3} \cdot \mathrm{py},\left[\mathrm{AuCl}_{2}(\mathrm{py})_{2}\right]$ $\mathrm{Cl} \cdot \mathrm{H}_{2} \mathrm{O}$, and $\left.\left[\mathrm{AuCl}_{2}(\mathrm{py})_{2}\right]\left[\mathrm{AuCl}_{2}\right]\right]$. Z Anorg Allg Chem. 1982;485(1): 65-80. German.

27. Zhang X-P, Yang G, Wang L, et al. Trichloro(2-phenylpyridine-KN) gold(III). Acta Cryst. 2007;E63(6):m1582.

28. Yam VW-W, Choi SW-K, Lai T-F, et al. Syntheses, crystal structures and photophysics of organogold(III) diimine complexes. J Chem Soc Dalton Trans. 1993;(6):1001-1002.

29. Corma A, Díaz U, Ferrer B, et al. Controlling the emission of blueemitting complexes by encapsulation within zeolite cavities. Chem Mater. 2004;16(7):1170-1176.

30. Lever ABP. Inorganic Electronic Spectroscopy. 2nd ed. Amsterdam: Elsevier; 1984.

31. Beck JS, Vartuli JC, Roth WJ, et al. A new family of mesoporous molecular sieves prepared with liquid crystal templates. J Am Chem Soc. 1992;114(27):10834-10843.

32. Mitchell DN, Godwin HA, Claudio E. Nanoparticle toxicity in Saccharomyces cerevisiae: a comparative study using Au colloid, Ag colloid, and $\mathrm{HAuCI}_{4} \cdot 3 \mathrm{H}_{2} \mathrm{O}$ in solution. Nanoscape. 2004;1(1) $59-69$.
International Journal of Nanomedicine

\section{Publish your work in this journal}

The International Journal of Nanomedicine is an international, peerreviewed journal focusing on the application of nanotechnology in diagnostics, therapeutics, and drug delivery systems throughou the biomedical field. This journal is indexed on PubMed Central,

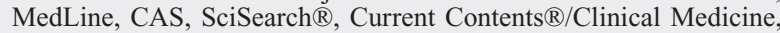

\section{Dovepress}

Journal Citation Reports/Science Edition, EMBase, Scopus and the Elsevier Bibliographic databases. The manuscript management system is completely online and includes a very quick and fair peer-review system, which is all easy to use. Visit http://www.dovepress.com/ testimonials.php to read real quotes from published authors. 